\title{
MEMÓRIAS E POSICIONAMENTOS EM ESTUDOS ORGANIZACIONAIS
}

\section{Roberto Fachin ${ }^{1}$}

\section{Resumo}

Este trabalho registra a evolução do pensamento organizacional no Brasil, sem a pretensão de um "tratado", a partir da memória resultante de vivências, dos dilemas, acordos e desacordos, e aponta os caminhos de sua evolução.

Palavras-chave: Estudos Organizacionais; Memórias; Evolução do Campo.

\section{MEMORIES AND POSITIONS IN ORGANIZATIONAL STUDIES}

\begin{abstract}
This study records the evolution of the organizational thinking in Brazil, ithout the pretense of a "Treated", from the memory resulting of the experiences, dilemmas, agreements and disagreements, and points the path for its development.
\end{abstract}

Keywords: Organization Studies; Memories; Development of the Field.

${ }^{1}$ Doutor em Ciências Humanas pela UFRGS. E-mail: rcfachin@portoweb.com.br

Revista Brasileira de Estudos Organizacionais · v. 1. n. 1, p. 4-16, jun. 2014, eISSN: 2447-4851

Sociedade Brasileira de Estudos Organizacionais 


\section{Introdução}

Convidado, ou melhor, desafiado a produzir um texto para o número inaugural da revista da Sociedade Brasileira de Estudos Organizacionais fundado em minhas memórias sobre a evolução da área, a tarefa pareceu ser fácil por um motivo apenas e difícil por uma dezena de outros.

Fácil porque, tendo a idade que tenho e ultrapassado o tempo de aposentadoria compulsória, tendo convivido com professorespesquisadores da área de Administração por cerca de 35-40 anos em congressos, contatos pessoais, leituras e produção de publicações fui, em muitos momentos, figura participante central em eventos de organização da área, podendo, portanto, comunicar muito do vivido na organização e desenvolvimento da área.

Difícil, no entanto, porque, para produzir com fidelidade todo esse material amealhado - na memória e nos livros produzidos ou consumidos - e retratar como entendo a evolução e o pensamento organizacional no Brasil, poderia parecer, aos que venham a ler este texto, que expresso a existência de um pensamento comum a uma comunidade de acadêmicos. Deixo claro que nunca cogitei a existência dessa unidade. Estou convicto de que existem tendências e buscas em comum, mas também ampla diversidade.

Para registrar, neste trabalho, um pouco da evolução do pensamento organizacional no Brasil, sem a pretensão de um "tratado", busquei na memória resultante de minha vivência, dos dilemas, acordos e desacordos, os caminhos de sua evolução.

\section{Os primeiros desacordos ou incertezas}

No contexto da Associação de Programas de Pós-graduação em Administração (ANPAD), cada área temática buscava o reconhecimento que vinha, primeiramente, da presença quantitativa nos congressos. E a quantidade dependia da abrangência das denominações encontradas.

Assim, a área temática foi ora chamada de Organizações, ora de Organizações/Estratégia, ora de Organizações (Macro) e Organizações (Micro), ora de Organizações (Teoria Organizacional) e Organizações (Comportamento Organizacional). Em várias ocasiões, houve articulações para separar Comportamento e instituí-lo como área independente, mas não chegou a ter sucesso e avançar a instâncias decisórias superiores. Estratégia esteve no início como integrante da área, mas com a ampliação do número de pesquisadores em Estratégia, tipicamente, houve nova subdivisão (Organizações e Organizações/Estratégia). Finalmente, Estratégia passou a ser uma área totalmente à parte. 
Estudos Organizacionais, como é hoje a denominação da área, recebeu plena adesão a partir da publicação, em 1998, do I volume da versão brasileira do Handbook de Estudos Organizacionais (1996). Os organizadores da edição original (Stewart Clegg, Cynthia Hardy e Walter Nord) afirmavam usar a expressão "estudos organizacionais" por ser um termo suficientemente amplo e não ter os problemas de termos como "teoria organizacional" ou "teoria das organizações" ou, mesmo, "ciência das organizações". Caldas, Fachin e Fischer, como organizadores da edição brasileira do Handbook of Organizational Studies, ${ }^{2}$ buscaram dar um sentido novo às traduções ao convocarem autores brasileiros para produzir "notas técnicas", comentando os diferentes artigos publicados no Handbook. É importante mencionar que a própria edição original do Handbook foi gestada inclusive com a participação de pesquisadores brasileiros da área de Organizações (Suzana Braga Rodrigues e Roberto Venosa), como mencionado na Introdução ao livro.

Em verdade, reconhece-se, com o uso de "estudos organizacionais" que não há "um" estudo, "uma" teoria, mas várias que competem entre si pelo lugar soberano, como existem correntes distintas de acadêmicos.

No próprio Handbook se encontra a afirmão de que a área pode ser vista como um locus de trabalho onde se desenvolvem narrativas múltiplas, com diferentes ontologias, epistemologias e metodologias. Rememorando esse nosso passado, entendi poder descrever a evolução da área e ser útil ao processo de desenvolvimento de uma sociedade de pesquisadores em estudos organizacionais.

Da minha vivência no processo de crescimento da ANPAD, concluo que o desenvolvimento da área se desenvolveu com base na produção acadêmica e nas interações que foram se estabelecendo, nas quais o contato com o conhecimento produzido no exterior e considerando importante o diálogo entre nacionais. Concluo que "um" pensamento organizacional tem que evoluir como uma "construção social", com diferentes ênfases e diferentes caminhos percorridos.

No entanto, tenho restrições sobre a suposição de existência de um "diálogo intenso" na área. Muitas vezes constatei, nas leituras da produção dos nossos acadêmicos, que pouco se cita e, consequentemente, pouco se lê os colegas brasileiros. As tendências mais recentes, de definir "áreas de interesse" para o encaminhamento de trabalhos nos congressos da área, parecem contribuir para o saneamento dessas deficiências, assim como a organização dos encontros através de variados grupos interinstitucionais.

\footnotetext{
2 A publicação em português do I volume surge com data de 1998, mas aparecendo nas livrarias realmente em 1999. Diferiu basicamente da edição original pela divisão do conteúdo em 3 volumes $(1998,2001$ e 2004$)$ e com vários capítulos complementados com "notas técnicas" escritas por pesquisadores brasileiros, comentando o texto original e introduzindo referências a produção acadêmica relevante em português.
} 
Os avanços em termos quantitativos começaram a ser realmente sentidos em 1987, pelo registro feito na Apresentação do $11^{\circ}$ Enanpad. O número de trabalhos em Organizações tinha aumentado de 6 trabalhos em 1985 para 24 em 1987 (de um total de 157 em 9 áreas temáticas). No parecer do então Presidente da ANPAD, notava-se um "aumento quantitativo e evolução qualitativa constante, em trabalhos cada vez mais analíticos" (FACHIN, 2006, p. 66).

O primeiro evento especializado no âmbito da ANPAD, a evidenciar a relevância da área, surge com a denominação de primeiro Encontro Nacional de Estudos Organizacionais (ENEO), realizado em Curitiba, no ano 2000. Foi, assim, consolidado o uso do termo "estudos organizacionais", introduzido pela publicação do livro supracitado.

Um comparativo (Tabela 1) dos diferentes EnEO's dá uma dimensão da área desde 2000:

Tabela 1: Publicações no EnEO - Período 2000 a 2012

\begin{tabular}{cccc}
\hline ENEO & Cidade & $\begin{array}{l}\text { Trabalhos } \\
\text { submetidos }\end{array}$ & $\begin{array}{c}\text { Trabalhos } \\
\text { apresentados }\end{array}$ \\
\hline I - 2000 & Curitiba & 146 & 53 \\
II - 2002 & Recife & 231 & 72 \\
III - 2004 & Atibaia, S.P. & 500 & 146 \\
IV - 2006 & Porto Alegre & 739 & 130 \\
V - 2008 & Belo Horizonte & 588 & 162 \\
VI - 2010 & Florianópolis & 622 & 176 \\
VII - 2012 & Curitiba & 462 & 133 \\
\hline
\end{tabular}

Fonte: elaborado pelo autor

\section{As análises feitas sobre a produção acadêmica}

Preocupação com uma produção qualificada

A preocupação com uma produção qualificada em estudos organizacionais teve estudos pioneiros e importantes, entre os quais podem ser sucintamente destacados os que serão mencionados abaixo.

a) O estudo de Machado, Cunha e Amboni (1990), sistematizado no artigo "Organizações: o estado da arte da produção acadêmica no Brasil", abrangeu o período 1985-1989 e identificou aumento quantitativo na produção acadêmica, na maior parte afiliada ao paradigma funcionalista e com a predominância de um foco prescritivo em vez de analítico.

b) O trabalho de Bertero e Keinert (1994), entre outras constatações, acentua a predominância de uma influência norte-americana com uma consequente falta de originalidade. 
c) Em Vergara e Peci (2003) foi tratado mais do método presente nas publicações brasileiras, acentuando a resistência, dos acadêmicos brasileiros, com a formulação e o teste de hipóteses e uma preferência por dados qualitativos ${ }^{3}$.

A seguir, registramos a preocupação, consignada em alguns trabalhos, com a influência norte-americana no ensino e na pesquisa em administração, bem como também a possível influência francesa na América Latina.

\section{A influência norte-americana}

Entre os estudos que registraram a importância da influência norteamericana, registramos os de Rodrigues e Carrieri (2000, 2006); Vergara (2006); Caldas e Alcadipani (2006).

A influência anglo-saxônica, particularmente a norte-americana, é esmiuçada no artigo de Rodrigues e Carrieri (2000, 2006), apresentado inicialmente no I ENEO (2000) e após publicado em outros veículos ${ }^{4}$. Entre várias constatações e conclusões, os autores afirmam que o pensamento anglo-saxônico predomina principalmente por influxo das multinacionais que passaram a atuar no Brasil, mas também, pela influência dos schoolars americanos que contribuíram na fundação dos programas gerenciais em nosso país. O artigo destaca, ainda, que, "embora no período de sua criação vários programas de mestrado não oferecessem finanças e marketing, quase todos ofereciam especialização em estudos organizacionais" (RODRIGUES e CARRIERI, 2006, p. 199). Tal constatação indicava, no seu entender, que "[...] nas décadas de 1970 e 1980 os especialistas de estudos organizacionais influenciaram a constituição da administração como área acadêmica e de pesquisa, pois foram os primeiros a ocupar posições de tempo integral nas universidades, onde havia escassez de profissionais com alta qualificação acadêmica nas subáreas de marketing e finanças".

$\mathrm{Na}$ interpretação de $\operatorname{Vergara}^{5}$ (2006, p.222), "[...] a construção do campo administrativo, forjado tanto pelas questões que uma economia em desenvolvimento suscita quanto pelos debates em salas de aula, mostrouse indissociável dos modelos e das orientações americanas". Anteriormente, Vergara (2000) já tinha constatado que as referências

\footnotetext{
${ }^{3}$ A preferência por abordagens qualitativas aparece, fortemente, quando do Encontro de Zacatecas, México, em 2000, repleto de acadêmicos de origem francófona (ver CHANLAT, FACHIN e FISCHER, 2006).

4 Entre várias apresentações e publicações anteriores, registramos a consignada em Chanlat, Fachin e Fischer (2006, p. 195-218).

5 Também apresentado originalmente no encontro de Zacatecas (2000) e, após, publicado no livro organizado por Bertero, Caldas e.Wood Jr., Produção científica em administração no Brasil: o estado-da-arte (São Paulo: Atlas, 2005, p. 35-49), sob o título "Estudos Organizacionais e produção científica brasileira".
} 
americanas representavam 61,05 \% das referências na análise organizacional brasileira.

O artigo de Vergara (2006, p. 219), na coletânea de Zacatecas (ver CHANLAT, FACHIN e FISCHER, 2006), também manifesta preocupação com "a vocação do brasileiro para imitar", como constatado por de Gilberto Freyre, nosso renomado sociólogo. Outros intelectuais brasileiros (Sergio Buarque de Holanda, Silvio Romero, Guerreiro Ramos) também foram citados e destacam essa tendência de imitação do estrangeiro. Questiona, portanto, se a produção científica em análise organizacional no Brasil tem revelado independência intelectual, tal que possa contribuir para o auto conhecimento do país, o reconhecimento de sua identidade e, a partir daí, para o seu autodesenvolvimento.

Já o artigo de Caldas e Alcadipani (2006, p. 262), nessa mesma coletânea de Zacatecas, abordam a "adoração do estrangeiro no Brasil" e discutem a gênese da referência norte-americana no imaginário e na cultura brasileira, analisando essa influência na gestão local através do referencial teórico pós-colonialista. O artigo de Caldas e Alcadipani aponta a obra de outros estudiosos (GUERREIRO RAMOS, 1981, 1983; CALDAS, 1997; BARBOSA, 1999; PRESTES MOTTA, ALCADIPANI e BRESLER, 2002) para relembrar que o chamado "estrangeirismo" é um de nossos traços culturais marcantes ${ }^{6}$. Em sequência, Caldas e Alcadipani (2006) acentuam nossa tradicional dependência de referenciais externos e o fato de que, pela inadequação de Portugal como um significante adequado, o brasileiro parece ter, desde o início, saído em busca de gringos alternativos ${ }^{7}$.

$\mathrm{Na}$ mesma linha de argumentação do texto de Vergara (2006) supracitado, Caldas e Alcadipani (2006) afirmam que foi durante a década de 1950 que as multinacionais norte-americanas espalharam-se pelo mundo e chegaram até o nosso país. Junto com as multinacionais e seus executivos, vinham embutidas as prescrições e referências do american way of life, bem como os ensinamentos da gestão norte-americana que deveriam ser difundidos e implementados no Brasil em nome do "desenvolvimento nacional" e da "edificação das instituições

\footnotetext{
${ }^{6}$ As referências, citadas por Caldas e Alcadipani, são as de: Alberto Guerreiro Ramos (A Nova Ciência das Organizações: Uma reconceituação da riqueza das nações. Rio de Janeiro: FGV, 1981; Administração e Contexto Brasileiro. Rio de Janeiro: FGV, 1983); Miguel Caldas (Santo de casa não faz milagre: condicionamentos nacionais e implicações organizacionais pela figura do 'estrangeiro'. In: PRESTES MOTTA, F. C.; CALDAS, M. Cultura organizacional e cultura brasileira. São Paulo: Atlas, 1997); Lívia Barbosa. Igualdade e Meritocracia. Rio de Janeiro: Editora da FGV, 1999); Fernando Prestes Motta, Rafael Alcadipani e Ricardo Bresler. Valorização do estrangeiro como segregação nas organizações, RAC - Revista de Administração Contemporânea, vol. 5 (Edição Especial): 59-79, dezembro, 2002).

7 Referidos são, pela sequência de preocupações, Portugal, o eixo Paris-Londres, um certo flerte com o referencial germânico, e a afirmativa de que "dentre essas duas potências coloniais, até em função de sua herança cultural e artística, pode-se dizer que a França foi a mais importante referência europeia nos primeiros séculos do Brasil Colônia e República. Outro artigo (FACHIN e CAVEDON, 2006), apresentado no encontro de Zacatecas, discute a influência francesa no Brasil.
} 
democráticas". Foram tais referências e ensinamentos que lentamente começaram a servir de modelo de eficiência para as organizações brasileiras.

A criação da Fundação Getúlio Vargas, incluindo a EBAP (1952) e a EAESP (1954), consolidou o processo de importação dos referenciais norteamericanos no ensino para as organizações no Brasil, através da formação de profissionais utilizando referenciais e recursos trazidos dos Estados Unidos. A FGV e suas escolas foram calcadas no modelo das universidades americanas, principalmente na Universidade de Michigan, e a maioria de seus professores foi qualificar-se naquele país (FISCHER, 1984).

A conclusão de Caldas e Alcadipani (2006, p. 291) é que

\begin{abstract}
Um dos elementos mais interessantes do caso da americanização do Brasil [...] é que tal neocolonização não foi realizada pela força da baioneta e dos canhões, como fez a Espanha nos demais países da América, ou a Inglaterra na Ásia, nem tampouco pela imposição de um modelo de colonização e de povoamento, como fez Portugal no Brasil colonial, pois a americanização foi realizada pela sedução, através da venda da imagem do americano no Brasil e do Brasil no americano. $\mathrm{O}$ nosso componente cultural de adoração ao estrangeiro catalisou o processo, e no fim das contas o "Tio Sam colocou bip-bop no nosso samba", por nosso livre e espontâneo consentimento.
\end{abstract}

\title{
Os dilemas e as propostas: a busca da autonomia intelectual e de um novo "centro" - o Brasil
}

Com o aumento dos programas de pós-graduação em administração no Brasil e dos participantes nos encontros nacionais da ANPAD, uma gama variada de pressões passou a invadir a academia de administração, entre elas, demandas internas da própria área - como (a) a pressão para que o campo de estudos organizacionais fosse também voltado à prática, e (b) os anseios para encontrar um caminho próprio, isento de "estrangeirismos"; e demandas reguladoras, como a demanda por mais "inserção internacional".

Esses dilemas precisavam gerar respostas e elas começaram a aparecer. Havia mudanças no cenário nacional, com o surgimento dos encontros especializados (os EnEOs); com a presença de novos docentes (formados inclusive nos novos doutorados brasileiros); e com a busca por temas novos, por audácia nos métodos e consequente busca de caminhos próprios.

Os Encontros Nacionais de Estudos Organizacionais foram introduzidos em 2000 e se repetiram a cada biênio. Da Apresentação do I ENEO: 
[A concepção do ENEO2000] leva em conta os principais questionamentos que têm sido feitos, em anos recentes, sobre o ensino e a pesquisa, sobre teoria e construção do conhecimento, sobre a fragmentação e a identidade do campo de estudos organizacionais no país" (p.iii). [...] No seu conjunto, os artigos escolhidos revelam o amadurecimento do campo de estudos organizacionais no país. A análise predomina sobre a prescrição. Os ensaios trazem contribuições relevantes. Os trabalhos teórico-empíricos tratam a metodologia de maneira mais cuidadosa, bem como procuram, de forma mais consistente, articular o quadro de referência conceitual com os dados empíricos (p.iv). O nível de análise dominante nos artigos selecionados é o organizacional, o que significa que se mantém a tendência de predomínio de estudos que utilizam perspectivas macro relativamente a aqueles que se detêm na verificação do relacionamento entre $\mathrm{o}$ indivíduo e a organização." (p.iv) (apud FACHIN, 2006, p. 124-125).

A realização, em sequência, de mais dois EnEOs (2002 e 2004) em diferentes partes do país, favoreceu o enfrentamento, no IV EnEO, de um dos aspectos menos trabalhados até então: a leitura de autores brasileiros pelos próprios brasileiros. A coordenadora local do Encontro, realizado em Porto Alegre, (2006), Maria Ceci Misoczky ${ }^{8}$, em diálogo com a coordenação nacional da Divisão de Estudos Organizacionais, da ANPAD, voltou a colocar ênfase na busca de um pensamento nacional, apoiada em palavras de Guerreiro Ramos e questionando qual deveria ser o foco da pesquisa organizacional - qual seria o "centro" dos estudos. O IV EnEO teve um tema orientador: "Apropriando teoria e prática - deslocando o centro" $^{\prime \prime}$. Começam a aparecer, com mais destaque, artigos tentando apropriar autores brasileiros que traçaram um quadro da cultura brasileira e, mesmo, buscavam algum apoio em ideias marxistas. Os autores brasileiros que começaram a ser mais valorizados e lidos foram intelectuais como Sergio Buarque de Holanda e Gilberto Freyre e professores de administração como Alberto Guerreiro Ramos, Fernando

\footnotetext{
8 Ver: MISOCZKY (2006).

9 A justificativa do tema orientador precisa ser lida dentro do seguinte trecho: "A apropriação da teoria e da prática pode ser entendida em diversos sentidos, entre os quais mencionamos: honrar nossa tradição intelectual, abordar temas relevantes para nosso tempo e espaço, interagir na sociedade enquanto acadêmicos e cidadãos preocupados com nosso contexto de vida e trabalho, incorporar traços de nossa identidade cultural enquanto produtores de conhecimento. Não se trata de adotar um nacionalismo ingênuo, nem o isolamento com relação ao que se realiza no restante do mundo. $O$ que se pretende é problematizar onde está o centro em torno do qual nos organizamos e produzimos. Ao fazê-lo, evidentemente, estamos levantando a possibilidade que esse centro se localize aqui. Aqui pode e deve ter vários sentidos: aqui no sul global, aqui na América Latina e em nossa proximidade com os países africanos - especialmente os de língua portuguesa, aqui no Brasil em sua enorme diversidade de locais e regiões [ênfase minha]. [...] Esperamos uma ampla variedade de contribuições, já que o tema central desta chamada de trabalhos expressa uma preocupação que, temos certeza, ronda nossa comunidade de estudiosos de organizações, ainda que não de modo claramente expresso. Portanto, se existe um desafio nesta proposta, é o de explicitarmos nossas posições, reflexões e incertezas sobre a apropriação da nossa produção acadêmica" (apud FACHIN, 2006, p. 128)
} 
Prestes Motta e Mauricio Tragtemberg. Delineava-se a busca de um "centro" para a produção intelectual em administração.

O encontro, inovador, mas com trabalhos em início de processo, teve adeptos entusiastas e também fortes críticas. A academia, de certa forma, dividiu-se entre partidários de uma decidida busca de inserção internacional, de qualidade inconteste, com produções alinhadas às grandes tendências encontradas na literatura norte-americana, ou mesmo, europeia, e um grupo, mais alinhado com estudos críticos, voltado à busca de um novo "centro" sem excluir a presença no cenário internacional. Em consequência, poder-se-ia dizer que havia uma luta pelo predomínio, com visões conflitantes e mesmo antagônicas. Tensões e dilemas entre os pontos de vista nacionalistas e críticos e uma maior adesão à produção internacional norte-americana e europeia.

De certa forma, retornava-se a uma proposição constante em texto de Bertero, Caldas e Wood (1999, p. 174):

\begin{abstract}
Compartilhamos a crença de que nós, pesquisadores na área de administração no Brasil, temos apenas duas alternativas, não necessariamente excludentes, para mudar o quadro desanimador que descrevemos acima: ou nos orientamos para desenvolver conhecimento local, que estrangeiros dificilmente poderiam produzir, reproduzir ou emular; ou nos orientamos para uma maior inserção no circuito internacionais como colaboradores da construção de conhecimento mundial no campo, procurando melhorar significativamente a qualidade de nossa produção.
\end{abstract}

\title{
A busca da América Latina
}

A busca por um novo "centro" para os estudos organizacionais surgiu mais ou menos ao mesmo tempo que uma busca por maior integração latino-americana. Tentando retratar a evolução do pensamento organizacional no Brasil, e em outros países latinos, realizou-se, há mais de dez anos, um colóquio sobre temas organizacionais em Zacatecas, México, procurando reunir pesquisadores de administração e sociologia francófonos, oriundos da França, Canadá (Québec), Bélgica, e América Latina (México e Brasil), sob a liderança de J.F.Chanlat, então na HECMontréal.

Desse evento, realizado em 2000, resultou uma coletânea (CHANLAT, FACHIN e FISCHER, 2006) de trabalhos escritos por autores da França, Canadá (Québec), Bélgica e América Latina (México e Brasil) editada em dois volumes: o primeiro volume tem o subtítulo “Olhar histórico e constatações atuais", nele se encontra a contribuição de Luis Montaño Hirose sobre "O estudo das organizações no México: uma perspectiva social"; o segundo volume reúne trabalhos em temas selecionados no 
Encontro por representar o estado do interesse dos participantes em temas organizacionais presentes no evento (poder, cultura, subjetividade e vida simbólica).

\section{Considerações finais: na direção de um pensamento coincidente e latino-americano}

Em 2008, na conferência magistral da Divisão de Estudos Organizacionais, no ENANPAD, realizado no Rio de Janeiro, foi trazido, diferentemente do que ocorria nos anos anteriores, um conferencista latino-americano: Eduardo Ibarra-Colado ${ }^{10}$ foi o escolhido porque tinha várias referências em periódicos estrangeiros. Naquele momento ele proferiu a conferência palestra intitulada "Cómo comprender y transformar los estudios organizacionales desde América Latina y no morir en el intento".

Entre as conclusões expressas na conferência, Ibarra-Colado advogou a necessidade de se

[...] propiciar un espacio para la circulación libre de las ideas, lo que implica revisar el acceso a publicaciones y revistas desde cada punto de nuestra América, a la vez de inducir comportamientos recíprocos en la materia. Esta preocupación se relaciona con discusiones muy importantes sobre los derechos de propiedad sobre el conocimiento y sobre sus alternativas, concretadas ya en el copyleft, el software libre, las licencias del tipo de creative commons o las publicaciones abiertas que empiezan a surgir como reacción al control de los Journals por parte de la industria editorial. [...] se plantea como la arena para la transformación de los Estudios Organizacionales en nuestra América. Su éxito dependerá de la capacidad que tengamos para articular redes que nos permitan re-unir-nos en torno a preocupaciones comunes, rescatando nuestras identidades, preocupaciones y proyectos. Debemos dejar atrás el traslado mecánico de los saberes generados en el mundo anglo-sajón y darles su lugar, restituyendo la simetría que debe al diálogo entre experiencias diversas. Debemos combatir la colonialidad epistémica, reconociéndola primero, y luego avanzando en el redescubrimiento de nuestra alteridad, restituyendo nuestra memoria histórica y la capacidad reflexiva que le devuelva originalidad de nuestras palabras. Sólo así podremos aspirar a contar con Estudios Organizacionales otros, los nuestros, sin naufragar en el camino, ni morir en el intento.

\footnotetext{
${ }^{10}$ Falecido, precocemente, em maio de 2013.
} 
Nota-se, nessas palavras, um pensamento que coincide com o atrás exposto sobre a evolução dos estudos organizacionais no Brasil.

Na direção de uma articulação maior dos estudos organizacionais na América Latina, foi se concretizando a Red de Posgrados de Investigación Latinos em Administración y Estúdios Organizacionales com atividades que incluem, entre outras, a realização de eventos.

A Red Pilares foi constituída em 2008, em reunião realizada em Medellín11, com a presença também de dirigentes da REMINEO - Red Mexicana de Investigadores en Estudios Organizacionales, entidade similar à nossa SBEO.

Dois congressos da Red Pilares já foram realizados: o primeiro, em Medellín, na Universidade EAFIT, em 2010; o segundo, em Quérétaro, México, em 2012. O terceiro será em Porto Alegre, no segundo semestre de 2014 com organização conjunta da UFRGS e da Unisinos. Espera-se que haja mais representantes brasileiros, além dos latino-americanos que foram o público dominante dos dois primeiros congressos. Entendo que a associação com a Red Pilares é um bom caminho a ser trilhado pela Sociedade Brasileira de Estudos Organizacionais na direção de institucionalizar a articulação dos estudos organizacionais na América Latina.

\section{Referências}

BARBOSA, L. Igualdade e meritocracia. Rio de Janeiro: Editora da FGV, 1999.

BERTERO, C. O.; CALDAS, M. P.; WOOD, T. Produção científica em administração de empresas: provocações, insinuações e contribuições para um debate local. Revista de Administração Contemporânea (RAC), v. 3, n. 1, p. 147-178, 1999.

BERTERO, C. O.; KEINERT, Tânia M. M. A evolução da análise organizacional no Brasil. Revista de Administração de Empresas (RAE), v. 34, n. 3, p. 81-90, 1994.

BERTERO, C. O. Ensino e pesquisa em administração. Coleção Debates em Administração. São Paulo: Thomson Learning, 2006.

CALDAS, M. P., ALCADIPANI, R. Americanização e pós-colonialismo: a gênese da referência norte-americana na cultura e na gestão no Brasil. In: CHANLAT, J.-F.; FACHIN, R.; FISCHER, T. Análise Organizacional:

\footnotetext{
${ }^{11}$ Ver a Declaração de criação em: http:/ / www.redpilares.org/sobre-la-red/Documents/declaracion-firmada-
} redpilares.pdf. 
perspectivas latinas. Vol. 1 - Olhar histórico e constatações atuais. Porto Alegre: Editora da UFRGS, 2006. p. 261-294.

CALDAS, M. Santo de casa não faz milagre: condicionamentos nacionais e implicações organizacionais pela figura do 'estrangeiro'. In: PRESTES MOTTA, F. C., CALDAS, M. Cultura organizacional e cultura brasileira. São Paulo: Atlas, 1997.

CHANLAT, J.-F.; FACHIN, R.; FISCHER, T. Análise organizacional: perspectivas latinas. Vol. 1 - Olhar histórico e constatações atuais. Porto Alegre: Editora da UFRGS, 2006. p. 261-294.

CHANLAT, J.-F.; FACHIN, R.; FISCHER, T. Análise organizacional: perspectivas latinas. Vol. 2 - Poder, Cultura, Subjetividade e vida simbólica. Porto Alegre/Brasil: Editora da UFRGS, 2007.

CLEGG, S.; HARDY, C.; NORD, W, (organizadores da edição original) CALDAS, M.; FACHIN, R.; FISCHER, T. (organizadores edição brasileira) Handbook de estudos organizacionais. Vols. I, II e III. São Paulo: Atlas, 1996, 2001 e 2004.

FACHIN, R., FISCHER, T. Organizational Literature, Brazil. In: International Encyclopedia of Organization Studies. Thousand Oaks: Sage, 2006.

FACHIN, R., Construindo uma Associação Científica: trinta anos da ANPAD - memórias, registros, desafios. Porto Alegre, [s.n], 2006.

FACHIN, R.; CAVEDON, N. A análise das organizações nos países francófonos: uma visão brasileira - francofilia ou francofobia? In: CHANLAT, J.-F.; FACHIN, R.; FISCHER, T. Análise Organizacional: perspectivas latinas. Vol. 1 - Olhar histórico e constatações atuais. Porto Alegre: Editora da UFRGS, 2006, p. 171-194.

FISCHER, T. Alice através do espelho ou Macunaíma em Campus Papagalli In: CHANLAT, J.-F.; FACHIN, R.; FISCHER, T. Análise Organizacional: perspectivas latinas. Vol. 1 - Olhar histórico e constatações atuais. Porto Alegre: Editora da UFRGS, 2006. P. 389-412.

FISCHER, T. O ensino de administração pública no Brasil: os ideais de desenvolvimento e as dimensões da racionalidade. Tese de Doutorado. São Paulo: USP, 1984.

FREYRE, G. Casa Grande e senzala. $13^{\mathrm{a}} \mathrm{ed}$. Rio de Janeiro: José Olympio, 1966.

GUERREIRO RAMOS, A. Administração e contexto brasileiro. Rio de 
Janeiro: FGV, 1983.

GUERREIRO RAMOS, A. The new science of organizations. Toronto: University of Toronto Press, 1981

HOLANDA, S. B. Raízes do Brasil. Rio de Janeiro: Editora José Olímpio, 1973.

MACHADO, C., CUNHA, V. C.; AMBONI, N. O estado da arte da produção acadêmica no Brasil. Trabalho apresentado no Encontro Anual da ANPAD, Florianópolis, 1990.

MISOCZKY, M. C. Sobre o centro, a crítica e a busca da liberdade na práxis acadêmica. Cadernos EBAPE.BR, v. IV, n.3, p. 1-13, 2006.

RODRIGUES, S. B.; CARRIERI, A. de P. A influência da abordagem anglosaxônica na análise das organizações no Brasil In: CHANLAT, J.-F.; FACHIN, R.; FISCHER, T. Análise Organizacional: perspectivas latinas. Vol. 1 - Olhar histórico e constatações atuais. Porto Alegre: Editora da UFRGS, 2006. p. 195-218.

RODRIGUES, S. B.; CARRIERI, A. de P. A tradição anglosaxônica em Estudos Organizacionais Brasileiros. Revista de Administração

Contemporânea, v. 5 (Edição Especial), 2001. p. 81-102.

VERGARA, S. C. Análise organizacional no Brasil: em busca da independência intelectual. In: CHANLAT, J.-F.; FACHIN, R.; FISCHER, T. Análise Organizacional: perspectivas latinas. Vol. 1 - Olhar histórico e constatações atuais. Porto Alegre: Editora da UFRGS, 2006. p. 219-238.

VERGARA, S. C., PECI, A. Escolhas metodológicas em estudos organizacionais. Organizações \& Sociedade, 2003. v. 10, n. 27.

VERGARA, S. C. A hegemonia americana em estudos organizacionais.Revista de Administração Pública (RAP), v.35, n.2. Rio de Janeiro/Brasil, 2001.

VERGARA, S.C.; PINTO, M. Referências Teóricas em Análise Organizacional: um estudo da nacionalidade dos artigos referenciados na literatura brasileira. Revista de Administração Contemporânea. V. 5 (Edição Especial), 2001. p. 103-121.

VERGARA, S. C. e CARVALHO Jr., D. S. Nacionalidade dos autores referenciados na literatura brasileira sobre organizações. In: Encontro Nacional dos Cursos de Pós-Graduação, 19, 1995. Anais... ANPAD, 1995. 